\title{
Risa y argumentación: algunos ejemplos en la literatura latina
}

\author{
Laughter and argumentation: some examples in Latin literature \\ Roberto Morales Harley ${ }^{1}$ \\ Recibido: 29/11/2016 / Aprobado: 23/5/2017
}

\begin{abstract}
Resumen
El artículo analiza los valores argumentativos de la risa en Horacio, Persio, Juvenal, Marcial y Petronio. Su propósito es determinar las diversas funciones de la risa y contrastarlas entre estos tres géneros literarios latinos: sátira, epigrama y novela. Para ello, se revisa un corpus constituido por las obras de los autores citados en busca de referencias a la risa y se establece una clasificación de valores argumentativos de la risa: a) promoción de la imagen del emisor, b) degradación de la imagen del destinatario, c) exposición de una oposición ante un punto de vista, d) exposición de una aprobación ante un punto de vista y e) establecimiento de una comunión con el auditorio. Como conclusión, se identificaron tres usos argumentativos de la risa en Horacio, uno en Juvenal, uno en Marcial y dos en Petronio.
\end{abstract}

Palabras clave: risa, argumentación, valores, sátira, literatura latina.

Abstract

This article analyzes argumentative values of the laughter of Horace, Persio Juvenal, Martial and Petronius in the narrative. The purpose is to determine the different functions of laughter and to contrast them among three Latin literary genres: Satire, Epigram and Novel. In order to do this, it is important to revise a corpus formed by pieces of works of these authors cited looking for references about laughter and to establish a classification of the argumentative values of laughter: a) promotion of the emitter's image, b) degradation of the recipient's image, c) exposition of an opposition towards a point of view, d) exposition of an approval of a point of view, and e) establishment of a communion with the audience. As a conclusion, three argumentative uses of laughter in Horace, one in Juvenal, one in Martial, and two in Petronius are described.

Key Words: laughter, argumentation, values, Satire, Latin literature.

\section{Introducción}

La voz risa deriva del lat. rìsus, - $\bar{u} s$, 'risa, risotada, carcajada', 'objeto de risa, irrisión'. Está atestiguada en esp. desde el s. XV como risa, y desde el s. XIII en la forma antigua riso (Segura, 2003: 668). Se relaciona con el verbo rīdeō, -ēre, $-s \bar{i}$, -sum, 'reír, reírse, 'sonreír,' 'reírse de algo, de alguien', 'burlarse, mofarse de' (Segura, 2003: 667). La forma nominal sonrisa no se encuentra en lat. clásico, pero provendría de la forma verbal sub-rìdeō, 'sonreír'.
Cerca de la risa se hallan los conceptos de lo cómico y el humor. Para Gil (1997: 30), la risa abarca un amplio espectro de fenómenos que van "desde el humor que provoca la sonrisa a la befa grosera que arranca la risotada" y lo cómico es "el estímulo causante de la risa" (1997: 29). Según González (2002-2003: 77) la risa es "sustancial al ser humano", depende de una capacidad "física" pero también "anímica", y puede evidenciar "diversos niveles de

\footnotetext{
${ }^{1}$ Profesor de la Escuela de Filología, Lingüística y Literatura de la Universidad de Costa Rica, Sede Rodrigo Facio. Correo electrónico: roberto.moralesharley@gmail.com
} 
humor". Por ejemplo, la diferencia entre rīsus, -ūs, 'risa', y cachinnus, -ī, 'carcajada' es de intensidad (González, 2002-2003: 78-79).

El humor, del lat. ùmor, -ōris, se refiere tanto a los fluidos corporales como al humorismo. Según Pollock (2003: 13-14), una única forma posee varios estratos de significación: uno superior, atenido al "campo semántico de la risa"; uno intermedio, como palabra que indica un "estado de ánimo o una disposición pasajera del espíritu”; y uno inferior, que se refiere a una "efluencia en el interior del cuerpo o a la salida del cuerpo". De manera esquemática, se podría decir que lo cómico es una de las posibles causas de la risa, y que el humor es uno de sus posibles resultados.

Algunas tipologías para la clasificación de estos fenómenos son los componentes de la risa (Gil, 1997) y las teorías del humor (Martínez et al., 2008). Para Gil (1997: 29), en el pensamiento antiguo, la risa cuenta con tres componentes: uno social, uno emocional y uno intelectual. El primero entiende la risa como un fenómeno de grupo, que incluso puede resultar en el castigo del individuo que no se acomode a dicho grupo (Gil, 1997: 34); el segundo toma en cuenta el relajamiento de tensiones, así como la pausa del trabajo y de las preocupaciones (Gil, 1997: 40); el tercero supone un aspecto estético que requiere de imprevisibilidad y engaño para funcionar (Gil, 1997: 43).

Si la risa tiene tres componentes, el humor, de acuerdo con Goodland y Spiegel (citados por Martínez et al. 2008: 1), se puede abordar desde ocho categorías principales: biológicas (conductas adaptativas), de superioridad (dominio del otro), de incongruencia (situaciones incompatibles), de sorpresa (disminución del humor en la reiteración), de ambivalencia (sentimientos incompatibles), de descarga (liberación de tensiones), de configuración (en la conciencia del individuo) y psicoanalíticas (ahorro de energía psíquica).
Desde la Antigüedad Clásica, la risa ha sido objeto de interés, desde diversas perspectivas: filosóficas, retóricas, fisiológicas, sociológicas, psicológicas. Entre los autores que se han dedicado a su estudio cabe destacar a los siguientes: presocráticos, sofistas, Platón, Aristóteles, Teofrasto, Demetrio de Falero, Plutarco, Descartes, Hobbes, Kant, Schopenhauer, Spencer, Emerson, Bain, Darwin, Wundt, Bergson, Sully, Freud. La lista no pretende ser exhaustiva.

Para efectos del presente trabajo, nos centramos en tres perspectivas de análisis: la risa y la retórica en los autores latinos (Cicerón, Quintiliano), la risa y los valores en la filosofía contemporánea (Stern), y, por último, la risa y la argumentación en la teoría de la argumentación (Perelman \& Olbrechts-Tyteca, Monsalve, Cattani, Conley).

\section{Marco teórico}

Paraíso (1997) señala a Cicerón (Orator 26, 87-89; De oratore II, 216, 235-236) y a Quintiliano (Institutio Oratoria VI, III, 7, 28, 37-38) como las fuentes más relevantes a propósito de la risa en la retórica latina. A continuación, se ofrecen los pasajes referidos:

Orator 26 [87] huic generi orationis aspergentur etiam sales, qui in dicendo nimium quantum valent; quorum duo genera sunt, unum facetiarum, alterum dicacitatis. Vtetur utroque; sed altero in narrando aliquid venuste, altero in iaciendo mittendoque ridiculo, cuius genera plura sunt; sed nunc aliud agimus. [88] illud admonemus tamen ridiculo sic usurum oratorem ut nec nimis frequenti ne scurrile sit, nec subobsceno ne mimicum, nec petulanti ne improbum, nec in calamitatem ne inhumanum, nec in facinus ne odii locum risus occupet, neque aut sua persona aut iudicum aut tempore alienum. 
Haec enim ad illud indecorum referuntur. [89] vitabit etiam quaesita nec ex tempore ficta, sed domo adlata, quae plerumque sunt frigida. Parcet et amicitiis et dignitatibus, vitabit insanabilis contumelias, tantum modo adversarios figet nec eos tamen semper nec omnis nec omni modo. Quibus exceptis sic utetur sale et facetiis, ut ego ex istis novis Atticis talem cognoverim neminem, cum id certe sit vel maxime Atticum (Cicero, 1911).

Admite también este género algunas sales, que son de admirable efecto en el decir. Las hay de dos géneros: facecia y dicacidad: una y otra puede usarse; la primera en las narraciones, la segunda para poner alguna cosa en ridículo. Los géneros son muchos, pero ahora no tratamos de eso. Sólo advierto que el ridículo no ha de ser demasiado frecuente, para que no caiga en truhanesco ni obsceno, para que no parezca mímico o petulante, para que no descubra mala intención; ni ha de recaer en calamidades, porque sería inhumano; ni en crímenes, para que la risa no ocupe el lugar del odio; ni ha de desdecir de la propia persona de la de los jueces, o de la ocasión, porque todo esto sería indecoroso. Han de evitarse asimismo las interrogaciones, que, cuando no son espontáneas, sino preparadas en casa, casi siempre parecen frías. Respetaráse la amistad y la dignidad; se desterrará del discurso toda afrenta y oprobio; sólo se perseguirá a los adversarios, y no a todos siempre y de la misma manera. Fuera de esto, pueden derramarse a manos llenas las sales y los chistes, lo cual yo no he visto hacer a ninguno de estos nuevos áticos, por más que sea muy propio del estilo ático (Cicerón, 1913).

Las sales son admisibles en la retórica. Por un lado, la incursión de lo cómico en lo serio es algo que ya los romanos tomaban en cuenta en las mōrēs māiōrum: junto a la gravitās, "sentido de la importancia de los asuntos entre manos", se encuentra la cōmitās, "atenuación de la excesiva seriedad" (Barrow, 2002: 24). Por otro, esa presencia es moderada, tal como lo evidencia la metáfora culinaria de la sal: la risa es como un aderezo. Y esta asociación se manifiesta también en el plano léxico: sāl, salis es 'sal, gracia, agudeza', 'finura espiritual, buen gusto,' 'agua salada, mar' (Segura, 2003: 680). Sus dos géneros son facētia, -ae, 'gracia, chiste, agudeza', 'burlas, bromas, pullas'; y dicācitās, -ātis, 'mordacidad, causticidad, humorismo'.

De oratore II [216] Illa autem, quae aut conciliationis causa leniter aut permotionis vehementer aguntur, contrariis commotionibus auferenda sunt, ut odio benevolentia, ut misericordia invidia tollatur. Suavis autem est et vehementer saepe utilis iocus et facetiae; quae, etiam si alia omnia tradi arte possunt, naturae sunt propria certe neque ullam artem desiderant: in quibus tu longe aliis mea sententia, Caesar, excellis; quo magis mihi etiam aut testis esse potes nullam esse artem salis aut, si qua est, eam tu potissimum nos docere (Cicero, 1902).

Las pasiones que el orador haya excitado, deberán de combatirse con otras pasiones contrarias, v.g., el odio con la benevolencia, y la misericordia con la envidia. A veces son de buen efecto los gracejos, chistes y sales; pero aunque todo lo demás sea materia de arte, esto es propio de la naturaleza y no puede enseñarse. Tú, César, que a mi parecer aventajas a todos en esto, podrás decirnos si es verdad que hay arte para el chiste, y caso de que le hubiere, tú sólo podrás enseñarlo (Cicerón, 1913).

Además de salēs hay iocī. Iocus, -ī es 'dicho o hecho gracioso, gracejo broma, chanza, donaire, gracia, chiste' (Segura, 2003: 397). Resulta significativo el énfasis hecho en el carácter innato 
de dichas facultades: la técnica ofrece las otras, pero no el humor. Cabe destacar que, en opinión de Mas (2015: 445), "la retórica ciceroniana de la risa plantea y desemboca en una ética y una táctica del humor atenta al estudio y posible codificación de los principios rectores de tan poderoso recurso, que debe utilizarse de manera conveniente, adecuada y decorosa”.

De oratore II [235] Ac ne diutius vos demorer, de omni isto genere quid sentiam perbreviter exponam. De risu quinque sunt, quae quaerantur: unum, quid sit; alterum, unde sit; tertium, sitne oratoris risum velle movere; quartum, quatenus; quintum, quae sint genera ridiculi. Atque illud primum, quid sit ipse risus, quo pacto concitetur, ubi sit, quo modo exsistat atque ita repente erumpat, ut eum cupientes tenere nequeamus, et quo modo simul latera, os, venas, oculos, vultum occupet, viderit Democritus; neque enim ad hunc sermonem hoc pertinet, et, si pertineret, nescire me tamen id non puderet, quod ne illi quidem scirent, qui pollicerentur. [236] Locus autem et regio quasi ridiculi-nam id proxime quaeritur-turpitudine et deformitate quadam continetur; haec enim ridentur vel sola vel maxime, quae notant et designant turpitudinem aliquam non turpiter. Est autem, ut ad illud tertium veniam, est plane oratoris movere risum; vel quod ipsa hilaritas benevolentiam conciliat ei, per quem excitata est; vel quod admirantur omnes acumen uno saepe in verbo positum maxime respondentis, non numquam etiam lacessentis; vel quod frangit adversarium, quod impedit, quod elevat, quod deterret, quod refutat; vel quod ipsum oratorem politum esse hominem significat, quod eruditum, quod urbanum, maxime quod tristitiam ac severitatem mitigat et relaxat odiosasque res saepe, quas argumentis dilui non facile est, ioco risuque dissolvit (Cicero, 1902).
Y para no deteneros más, diré en pocas palabras lo que siento. Cinco cosas hay que preguntar acerca de la risa: primera, lo que es; segunda, de dónde procede; tercera, si es propio del orador hacer reír; cuarta, hasta qué punto; quinta, cuántos son los géneros de ridículo. En cuanto a lo primero, es decir, a lo que la risa misma es, y cómo se excita y mueve, y dónde reside y cómo estalla de repente sin que podamos contenerla, y de qué suerte se comunica a los costados, a la boca, a las venas, al rostro y a los ojos, averígüelo Demócrito, pues a mi propósito nada importan esas cosas, y aunque importaran, no tendría yo reparo en confesar mi ignorancia en lo que ignoran los mismos que prometen enseñarlo. El lugar, digámoslo así, y la región de lo cómico (y esta es la segunda cuestión), consiste en cierta torpeza y deformidad; pues casi siempre se reduce el chiste a señalar y censurar no ridículamente alguna ridiculez. Y viniendo al tercer punto, diré: que es muy propio del orador mover la risa, ya porque la misma hilaridad concilia la benevolencia de los que participan de ella; ya porque admiran todos la agudeza, contenida a veces en una sola palabra, especialmente en la réplica, ya que no en la invectiva; ya porque quebranta las fuerzas del adversario y le estorba y le aterra y le confunde; ya porque da a entender que el mismo orador es un hombre culto, erudito y urbano; pero sobre todo, porque mitiga y relaja la severidad y tristeza, y deshace en juego y risa la odiosidad que no es fácil destruir con argumentos (Cicerón, 1913).

A la manera de los locī retóricos (quis, quid, ubi, quibus auxilī̄s, cūr, quōmodo, quando), se proponen cinco preguntas. Sobre la primera (¿qué es la risa?), Cicerón admite no tener respuesta. En cuanto a la segunda (¿de dónde procede?), cita dos fuentes: turpitūido, -inis, 'fealdad, deformidad, fealdad moral, vergüenza, indignidad, deshonor, deshonra, infamia, vileza' (Segura, 2003: 801) 
y déformitās, -ätis, 'deformidad, fealdad, defecto, vicio', 'deshonor, deshonra, infamia, indignidad, vergüenza' (Segura, 2003: 198). Ambos conceptos implican una valoración negativa, no solo física, sino también moral: la risa se relaciona con los valores. En relación con la tercera pregunta (¿es propio del orador hacer reír?), señala que el orador se vale de la risa para la captātiō benevōlentiae, porque lo eleva al tiempo que rebaja al adversario, y porque relaja el ambiente. Esto es algo que la risa hace mejor que los argumentos, i. e., constituye una función argumentativa de la risa. No tomamos en cuenta las dos últimas preguntas, aspecto en el que también se podría profundizar.

Institutio Oratoria VI, III [7] neque enim ab ullo satis explicari puto, licet multi temptaverint, unde risus, qui non solum facto aliquo dictove, sed interdum quodam etiam corporis tacta lacessitur. praeterea non una ratione moveri solet, neque enim acute tantum ac venuste sed stulte, iracunde, timide dicta aut facta ridentur; ideoque anceps eius rei ratio est, quod a derisu non procul abest risus (Quintilian, 1921).

pues aunque muchos intentaron buscar la causa de la risa, me parece que no dieron con ella; porque ésta no solamente se excita con palabras y acciones, sino con cierto aire del cuerpo. Ni tampoco siempre de una misma manera, porque no solamente nos reímos de lo que se dice con gracia y agudeza, sino a veces de una sandez, de una acción o palabra dicha con ira o timidez. Y no es la menor dificultad si consideramos que la irrisión se confunde con la risa (Quintiliano, 2004).

El pasaje menciona algunas causas de la risa: factum, dictum, tāctum. A la distinción tradicional entre hechos y dichos, se suma el manejo (del cuerpo). Esta actiō o performance del elemento desencadenante de la risa es determinante: según el modo en que se cuente un chiste, este puede resultar más o menos cómico. A partir de tales causas, se podrían sugerir ciertos tipos de risa, los

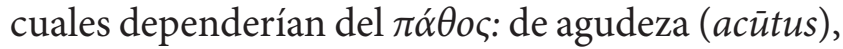
de ingenio (venustus), de estulticia (stultus), de ira (ìrātus), de timidez (timidus). También distingue Quintiliano entre rīsus y dērīsus. Dērīsus, -ūs deriva de dèrìdeō, -ère, -sī, -sum, 'burlarse de, reírse de', bromear, reír', 'ser objeto de burlas, de risa, de menosprecio' (Segura, 2003: 207).

Institutio Oratoria VI, III [28] refert, his ubi quis utatur. nam in convictibus et cotidiano sermone lasciva humilibus, hilaria omnibus convenient. laedere nunquam velimus, longeque absit propositum illud potius amicum quam dictum perdendi. In hac quidem pugna forensi malim mihi lenibus uti licere; quanquam et contumeliose et aspere dicere in adversarios permissum est, cum accusare etiam palam et caput alterius iuste petere concessum sit. Sed hic quoque tamen inhumana videri solet fortunae insectatio, vel quod culpa caret vel quod recidere etiam in ipsos, qui obiecerunt, potest (Quintilian, 1921).

Va también a decir no poco el lugar donde los decimos. En los convites y en las conversaciones los chistes lascivos sólo caen bien en gente humilde; los alegres en cualquiera; pero guardémonos siempre de zaherir y no sigamos aquello de más quise perder un amigo que quedarme con la gracia en el buche. En estas peleas del foro me abstendría yo de las que puedan ofender a alguno; aunque está tolerado el zaherir y ofender al contrario, el acusarle abiertamente y tirarle a degüello si hay razón. Sin embargo de esto, parece una inhumanidad el insultarle en su abatimiento, o ya porque está inocente, o ya porque si está culpado, el que le zahiere puede caer en la misma miseria (Quintiliano, 2004). 
Para la risa, también es importante el contexto: según el sitio en que se cuente un chiste, este puede resultar más o menos cómico. La ideología compartida determinada la (in)adecuación, por ejemplo, de temas tabú. Así, en situaciones serias, las bromas lascivas (lascīvia) solo agradan a los humildes, pero las alegres (hilaria) son bien recibidas por todos. Ahora bien, siempre dependerá del contexto: una broma alegre podría no ser bien recibida en un funeral. Cabe destacar el consejo de Quintiliano de evitar las ofensas en el foro, lo cual califica de inhumano. Se trata esto de una valoración.

Institutio Oratoria VI, III [37] risus igitur oriuntur aut ex corpore eius, in quem dicimus, aut ex animo, qui factis ab eo dictisque colligitur, aut ex iis, quae sunt extra posita. intra haec enim est omnis vituperatio; quae si gravius posita sit, severa est, si levius, ridicula. haec aut ostenduntur aut narrantur aut dicto notantur. [38] rarum est, ut oculis subiicere contingat, ut fecit C. Iulius; qui, cum Helvio Manciae saepius obstrepenti sibi diceret, etiam ostendam, qualis sis. isque plane instaret interrogatione, qualem se ostensurus esset, digito demonstravit imaginem Galli in scuto Cimbrico pictam, cui Mancia tum simillimus est visus (Quintilian, 1921).

Excitamos la risa ridiculizando los defectos del cuerpo o del ánimo del contrario, esto es, sus dichos y acciones, u otras cosas que están fuera del ánimo y cuerpo. Cuanto vituperamos a esto se reduce; $y$ si esto se hace con gravedad, será una vituperación seria, si con gracia se llama ridiculizar. Los defectos, o se descubren, o se cuentan, o se notan con alguna chanza. Rara vez sucede que lo que ridiculizamos lo hagamos presente a los ojos, como lo hizo C. Julio. Diciendo éste a Helvio Mancia: Yo te haré ver a quién te pareces, le importunaba que se lo dijese. Julio entonces señalando con el dedo, le mostró la imagen de un francés pintado en un escudo de los que trajo Mario de la guerra contra los cimbros, que estaba de muestra sobre una tienda. Entonces se vio que Mancia no le quitaba pinta (Quintiliano, 2004).
La risa se origina ex corpore o ex animō (o de algo externo al cuerpo y al alma). Depende, pues, de una ridiculización de algún elemento físico o espiritual del ser. La presencia/ausencia de la risa determina, respectivamente, una ridiculización (rīdiculum) o un vituperio (vituperātiō). Pocas veces estas operaciones alcanzan un efecto visual ( $\dot{v} \alpha \alpha \rho \gamma \varepsilon \iota \alpha)$, mas, cuando lo hacen, consiguen una función retórica.

A. Stern ofrece una teoría que posibilita la conjugación de varios de los elementos que se han rescatado de los autores clásicos. Desde este enfoque axiológico, los valores constituyen un punto de contacto entre la risa y la argumentación. Los valores son "relaciones de objetos con el sujeto apreciante" (Stern, 1950: 22). A su vez, la risa es "un juicio de valor, un juicio de valor negativo concerniente a una degradación de valores" (Stern, 1950: 51). Risa y valores guardan una relación causal y reversible: una degradación de los valores puede provocar la risa, así como una risa puede provocar la degradación de los valores (Stern, 1950: 53).

Stern (Filosofía de la risa y el llanto) parte del modelo de Bergson (La risa), centrado en la risa producida por lo cómico, y amplía la perspectiva, al incorporar "todo incidente y todo proceder que desvían nuestra atención de un valor a un no-valor, o de un valor intrínseco a un valor instrumental, equivaliendo ambos casos a una degradación de valores que provoca el instintivo juicio de valor negativo que es la risa" (Stern, 1950: 56). Con lo cómico como punto de referencia, la risa se divide en risa degradante de los valores positivos, propia de lo cómico, y risa devaluante de los valores negativos, más allá de lo cómico. Esta última incluye los siguientes tipos:

1. la risa de alegría: "mediante nuestra risa buscamos devaluar todo lo doloroso y lo serio que se interponían entre nuestra aspiración a un valor positivo determinado y su realización, a fin de experimentar en toda su intensidad el valor positivo que acabamos de alcanzar" (Stern, 1950: 160). 
2. la risa de alegría maligna (en al. Schadenfreude): "la pérdida de los valores sufrida por la persona detestada constituye el objeto de una degradación de valores por parte de la persona que detesta. Es así que la segunda persona ríe, ríe de alegría maligna, allí donde la primera llora o tiene ganas de llorar (Stern, 1950: 169).

3. la sonrisa de compasión: "superponiéndose uno al otro, estos opuestos juicios instintivos de valor [sc. la sonrisa, negativo; la compasión, positivo] darán nacimiento a la sonrisa de piedad" (Stern, 1950: 177).

4. la sonrisa de modestia: "es la manifestación menor de reconocimiento, mediante la cual la persona elogiada debe devaluar ficticiamente su propio valor, a fin de hacérselo perdonar" (Stern, 1950: 180-181).

5. la sonrisa de urbanidad: "está llamada a devaluar el valor negativo del daño que le [sc. al vecino] hemos causado" (Stern, 1950: 185).

6. La sonrisa de pesar: "está llamada a degradar un poco el valor positivo del bien al que la otra persona aspira, a fin de hacerle parecer su carácter irrealizable como menos doloroso" (Stern, 1950: 194).

7. la sonrisa de resignación: "mediante su sonrisa de resignación, hace 'como si' el valor positivo del bien negado fuera desdeñable, lo mismo que el valor negativo de la negativa" (Stern, 1950: 195).

8. la sonrisa de aliento: "al sonreír de manera alentadora, la personalidad que posee esa alta dignidad moral y social, busca devaluar su importancia en la conciencia de su visitante" (Stern, 1950: 197).

9. la sonrisa que caracteriza la vida erótica: "la mujer que sonríe al hombre que le place, no busca degradar un valor positivo, sino devaluar un valor negativo. A saber, el valor negativo de la convención social que mantiene al hombre distanciado de la mujer" (Stern, 1950: 201-202).
10. la sonrisa irónica: "la ironía podría ser considerada como una puesta en juicio, una puesta en juicio ficticia de ciertos valores" (Stern, 1950: 209).

11. la sonrisa escéptica: "busca devaluar, e incluso a veces degradar, el sistema de valores en el cual cree el interlocutor, y del cual dudamos" (Stern, 1950: 212).

12. la sonrisa amarga: "devalúa un valor positivo, con el amargo pesar de tener que devaluar lo que se aprecia altamente" (Stern, 1950: 212).

13. la sonrisa solicitante: "llamada a devaluar el valor negativo que impongo a aquel a quien pido alguna cosa, la sonrisa solicitante debe degradar también el valor positivo del bien que constituye el objeto de mi solicitud" (Stern, 1950: 213).

14. la sonrisa de consuelo: "mediante nuestra sonrisa, buscamos devaluar el valor negativo del sufrimiento" (Stern, 1950: 214).

Al menos 3 de estos tipos son susceptibles de un análisis lingüístico: la sonrisa de modestia, la sonrisa de urbanidad y la sonrisa solicitante guardan una estrecha relación con los planteamientos de la cortesía verbal, en tanto su objetivo es no afectar la imagen negativa del interlocutor. $\mathrm{Y}$ al menos 2 de ellos apuntan hacia una función argumentativa: la sonrisa irónica y la sonrisa escéptica ofrecen valoraciones acerca de opiniones que pueden tener la forma de argumentos.

La teoría de la argumentación o nueva retórica ha evidenciado cierto interés por el análisis de la risa en este ámbito, que continúa siendo objeto de investigación. La obra de Perelman y OlbrechtsTyteca (Tratado de la argumentación) surge en un contexto filosófico particular: "la nueva retórica forma parte de la gran corriente de pensamiento que desde mediados de la década de los cuarenta reaccionó contra los excesos teóricos del empirismo lógico, de un lado, y contra las ideas retardatarias y absolutistas en la política europea, del otro" (Monsalve, 1992: 13). 
Esta nueva retórica se propone enmendar los métodos de análisis retórico, el cual, en opinión de los autores, se había desviado de su camino por dos errores: a) "en 1555, Pedro de Ramos presenta las artes del discurso, el Trivium, de la siguiente manera: la gramática como el arte de hablar bien, la dialéctica como el arte de razonar correctamente y la retórica como el arte del uso elocuente y adornado del lenguaje" (Monsalve, 1992: 43-44); y b) "desde mediados del siglo XIX -y como resultado de las concepciones kantianas y de los lógicos matemáticos- la lógica se ha identificado con la lógica formal, es decir con la analítica aristotélica, y se ha abandonado paulatinamente la dialéctica, lo que constituiría un error simétrico al de Pedro de Ramos" (Monsalve, 1992: 44).

La obra de Monsalve (Teoría de la argumentación) ofrece una síntesis bastante útil del pensamiento de Perelman, pues maneja también sus otras producciones. Con respecto a la argumentación, las principales ideas se pueden resumir de la siguiente manera:

1. La argumentación depende de juicios de valor: "En la argumentación, un (o algunos) valor (es) puede (n) ser cuestionado (s), pues la esencia misma de la argumentación es logar la adhesión a unas determinadas tesis, lo que significa, por definición, privilegiar unos puntos de vista que se ordenan de acuerdo con una determinada valoración en oposición a otra" (Monsalve, 1992: 77).

2. Los juicios de valor se fundamentan en valores abstractos: "Perelman y OlbrechtsTyteca piensan que en Occidente la moral se ha construido, en términos generales, en torno a los valores abstractos, pues ha girado siempre con base en la observancia de reglas de conducta válidas para todas las circunstancias. En algunas culturas orientales se ha construido alrededor de valores concretos, como en el caso de Confucio, que plantea cinco deberes de obligación específica, de este orden: entre gobernantes y gobernados, entre padres e hijos, entre hermano mayor y hermanos menores" (Monsalve, 1992: 78).

3. Los valores se organizan en jerarquías: "En realidad, en la argumentación las jerarquías son más importantes que los valores mismos porque éstos son comunes a muchos auditorios. La distinción no se da tanto entre los valores que admiten sino en la manera como se jerarquizan" (Monsalve, 1992: 80).

4. El ridículo puede tener una función argumentativa: "El ridículo desempeña un papel bien especial en la argumentación porque expresa una sanción social cuando quien ha transgredido una regla admitida o asume una actitud excéntrica o se opone a la experiencia o a la lógica, no es juzgado por su falta, merecedor de una sanción más fuerte. La argumentación cuasilógica por el ridículo se asemeja a la demostración formal por reducción al absurdo" (Monsalve, 1992. 122).

5. La ironía permite argumentaciones por el ridículo: "La figura clásica del razonamiento por el ridículo es la ironía en la que "se quiere hacer entender lo contrario de lo que se dice" (Monsalve, 1992: 123).

A este punto, conviene definir el ridículo (la reducción al absurdo en un sentido amplio) y la ironía:

Reducción al absurdo. En lógica clásica, es el nombre de una regla de deducción que consiste en probar $\mathrm{p}$ tomando como una de las premisas la negación de p y demostrando que, en conjunción con premisas previamente aceptadas (o, en su caso, axiomas), se sigue una contradicción... En sentido amplio, podemos llamar 'reducción al absurdo' a cualquier estrategia argumentativa que, asumiendo, por mor del argumento, cierta 
tesis que se quiere refutar (o su negación, caso de pretender argüir en su favor), llegue a una conclusión obviamente falsa (trátese o no de una contradicción) (Donato, en Vega y Olmos, 2012: 22-24).

Ironía. La ironía es el uso de una palabra de manera que transmita el significado opuesto a su significado literal... Es una contradicción admitida en tanto que manifiesta $y$, por lo tanto, comprensible y funcional en la comunicación. Es, en rigor, la transgresión patente de una regla tácita según la cual quien habla tiene que decir cosas que considera sensatas y verdaderas. Lo que permite entender que uno ha dicho $x$, pero quiere decir lo opuesto, no-x, es la naturaleza racional y cooperativa de la conversación, en particular del llamado principio de cooperación... A veces se relaciona con la risa -que ya de por sí es un medio de persuasión-, la broma o la disimulación... En la ironía, el doble sentido tiene un valor argumentativo y explica su impacto. Con frecuencia, su víctima toma el mensaje al pie de la letra, lo que la torna ridícula de cara al auditorio, sobre todo si aquella tarda en captar la ironía, y esto es lo que le confiere cierta finura e incluso crueldad. Desde un punto de vista retórico, la ironía refuerza la conexión entre el hablante y el público. En caso de que perciba la ironía, el auditorio puede agradecer su poder y mostrarse más dispuesto a aceptar las tesis del argumentador. Es obvio que ese refuerzo es importante y también posee un valor argumentativo. Por ello, la ironía es, sin duda, la figura retórica que se integra mejor en la argumentación (Alcolea y Cattani, en Vega y Olmos, 2012: 323-236).

En su vertiente argumentativa, la ironía se asemeja al humor, pero subsiste una diferencial de grados. Al respecto, escribe Cattani que "la persuasión que se logra -cuando se logra-con el humor es muy rápida, pero en esta materia el humor debe cogerse con pinzas. Para convertirse en argucia argumentativa o en argumento agudo el humor ha de ser pertinente y expresivo y cuidarse mucho de parecer intempestivo y superficial" (Cattani, 2003: 185). Y también que "más difícil es emplear la ironía, que pertenece al mismo registro que el humor, pero no se identifica con él. Bien dice Georges Elgozy: 'La ironía es un arma ofensiva; el humor, un escudo protector'. Un flechazo punzante, un latigazo o peor aún el sarcasmo despectivo pueden provocar la antipatía de los partidarios del adversario" (Cattani, 2003: 186-187).

Humor e ironía son conceptos claves para determinar el valor argumentativo de la risa. Desde una perspectiva retórica, las funciones de la risa son las siguientes (Cattani, 2003: 184):

1. tranquiliza el ambiente; reduce las tensiones; atenúa y desdramatiza;

2. reaviva la atención;

3. atestigua el ingenio de quien sabe emplearla, que ofrece una imagen de persona suficientemente distanciada y desencantada, brillante y dueña de la situación; por tanto, funciona como mecanismo de promoción personal;

4. produce en el auditorio una corriente de simpatía y establece una relación de complicidad y connivencia entre el disputador ingenioso y el público; consolida la relación con el auditorio;

5. entretiene e incluso divierte; sirve para contrarrestar la tensión de un momento difícil;

6. contribuye a rebajar al adversario e incluso puede ponerlo en ridículo.

La función 3 se asocia con el $\tilde{\eta} \theta$ oc; la 1 y la 2 ,

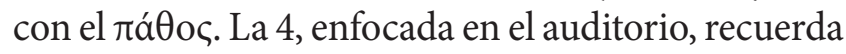
la noción de figuras de comunión de Perelman y Olbrechts-Tyteca, las cuales poseen una función argumentativa, e incluso el concepto de información pragmática. Finalmente, la 5 corresponde a lo cómico, mientras que la 6 está más allá de lo cómico. 
El punto 6, el ridículo, tiene en la argumentación una función similar a la de la reducción al absurdo en la demostración; por tanto, cuenta con un valor argumentativo.

El chiste también puede tener valor argumentativo. A diferencia de la risa, en el chiste sí hay lenguaje articulado. De acuerdo con Conley (2004), las bromas guardan un paralelismo, tanto en forma como en contenido, con los argumentos. Seguidamente, se presentan tres de los elementos a los que se debe prestar atención:

1. To begin with, one has to be very careful about appropriateness as regards subject matters and the audience you're telling the joke to... Jokes depend on deeply shared knowledge -commonplacesboth of particulars and of stereotypes... So composing a joke or repeating it involves the same sort of detailed inquiry into audience beliefs and values and situational constraints as argumentation does (Conley, 2004: 267).

2. One needs to be careful, too, not to tell jokes that are inordinately long (Conley, 2004: 67).

3. Writing a joke -or even just retelling onerequires a delicate balance between the expected and the unexpected, both of them considered in terms both of conventional expectations and expectations generated by the joke itself (Conley, 2004: 268).

La primera afirmación no solo retoma, mutatis mutandis, la comunión con el auditorio o la información pragmática compartida por las partes, sino que también destaca el papel de puente que cumplen los valores. Las otras dos se vinculan a lo que la crítica retórica llama exigencia del contexto. La parte contextual, que generalmente ocupa el lugar de la premisa mayor en los silogismos, posibilita relacionar bromas y argumentos: "one way of putting it would be to propose that extended arguments -rhetorical arguments, if you will- even when they are composed and arranged around a complete, three-proposition syllogisms are, like all jokes, radically enthymematic" (Conley, 2004: 268).

Entonces, si se completa el silogismo en las bromas y en los argumentos, ¿se logra su comprensión? Conley considera que no: "this is one reason why it does not do to reduce an argument to some unambiguous complete or incomplete syllogism. As a matter of fact, even an 'unambiguous' 'complete' syllogism is, in an important respect, enthymematic" (Conley, 2004: 268-269). Nosotros proponemos que sí, pero solo parcialmente. Conley tiene razón al considerar que "another reason it is a mistake to imagine that one truly 'gets' an argument by reducing it to some implicit core syllogism (and is justified in rejecting the argument if there is no core syllogism) is that doing so erects a false dichotomy between form and content, between manifest and latent, between surface and 'deep' structure" (Conley, 2004: 269). La alternativa que proponemos es, no reconstruir la premisa de un silogismo, sino la información pragmática de un acto de habla. Esta permite la comprensión del aspecto contextual y cultural del chiste, así como de la risa.

\section{Metodología}

A partir de los planteamientos teóricos precedentes, se podrían sugerir, tentativamente, cinco valores argumentativos de la risa: a) promoción de la imagen del emisor, b) degradación de la imagen del destinatario, c) exposición de una oposición ante un punto de vista, d) exposición de una aprobación ante un punto de vista y e) establecimiento de una comunión con el auditorio. Las categorías combinan elementos de la retórica:

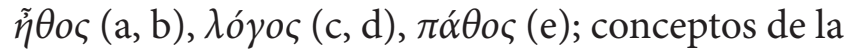
pragmática: imagen, emisor, destinatario; y nociones de la argumentación: punto de vista, comunión. Algunos ejemplos, de un supuesto debate: uno de los contendientes se ríe de un insulto del otro, en vez de enojarse (a); uno de los contendientes se ríe de una estadística errónea del otro, en la que la suma 
de los porcentajes sobrepasa en cien (b); uno de los contendientes se ríe de una opinión incompatible con su propia ideología, que el auditorio conoce de antemano (c); uno de los contendientes se ríe de un ejemplo del otro, cuyo sentido es compatible con su propia ideología (d); uno de los contendientes ríe de un acontecimiento externo, como la interrupción de la corriente eléctrica, el sonido de un trueno, algún comentario de la audiencia (e).

La meta de esta propuesta es determinar y comparar algunas funciones de la risa, particularmente sus valores argumentativos, en diversos géneros y autores de la literatura latina: la sátira (Horacio, Persio, Juvenal), el epigrama (Marcial) y la novela (Petronio). Un análisis de un elemento en tres géneros distintos debe comenzar por establecer las relaciones entre estos géneros que posibilitan la comparación. En este caso, el punto en común entre sátira, epigrama y novela es el espíritu satírico. La sátira debe, por tanto, ser el punto de partida. Esta, en un sentido restringido, es un género literario menor, el único propiamente romano, que se divide en formal (en verso) y menipea (verso y prosa); pero, en un sentido amplio, es un estilo literario, que se divide en libelo (ataque personal) y farsa (visión fantástica del mundo), o, incluso, es un modo de vida, caracterizado por el espíritu satírico.

Hay muchos modos de considerar la vida y la sátira es uno de ellos. Contemplar el mundo con una mezcla de risa e indignación no es el más noble ni el que produce mayor número de obras de arte excelsas; pero este es el punto de vista de la sátira. La sátira comienza con una postura mental de crítica y hostilidad, por un estado de irritación causada por los ejemplos inmediatos del vicio y de la estupidez humanos y aunque las ocasiones que se nos presentan para dar rienda suelta a la sátira son infinitas e inherentes a la condición humana, los impulsos que incitan a ella son básicos de la naturaleza humana (Hodgart, 1969: 10).
En la sátira, la risa puede determinar una degradación de valores: "el enojo del satírico se ve modificado por su sentido de superioridad y desprecio hacia su víctima; su aspiración es que ésta se humille y la mejor forma de conseguirlo es la risa despreciativa" (Hodgart, 1969: 10). Dicha degradación, a su vez, puede tener un valor argumentativo, e. g.: degradación de la imagen del destinatario o exposición de una oposición ante un punto de vista.

El epigrama sería una composición satírica breve: "las dos formas más breves de la sátira, aunque de ningún modo las más simples, son el aforismo y el epigrama" (Hodgart, 1969: 150); y la novela, una composición satírica más extensa: "la novela satírica, si ha de tener éxito, tiene que ser breve" (Hodgart, 1969: 214). La precisión formal sobre la extensión se basa en la idea de que el ingenio se desarrolla en espacios breves.

Carmen (2010: 215) señala que "entre los griegos, la risa tuvo función relajante en la épica; insultante en la poesía yámbica y fue fin fundamental de la composición cómica”. Por su parte, Muñoz (1992: 32) agrega que, en Roma, "entre los géneros literarios la satura parece haber sido el primero que se sirvió del humor". Además, defiende la teoría de que el humor es característico de las sociedades en decadencia (Muñoz, 1992: 44). Esta idea aplica para los epigramas y para la novela, pero no para todos los satíricos (e.g. Horacio en época de Augusto). En la bibliografía consultada, no se ha encontrado ningún enfoque argumentativo de la risa en estos géneros.

Para desarrollar tal aspecto, se parte de la hipótesis de que la risa en la sátira, el epigrama y la novela no posee una única función cómica, sino que existen en estos géneros funciones particulares de la risa, según sus contextos de uso, que pueden servir para fines distintos, susceptibles de una clasificación. 


\section{Análisis}

A continuación, se analizan algunas de las funciones de la risa en tres autores satíricos (Horacio, Persio, Juvenal). Se siguen, en todos los casos, los textos originales, así como las traducciones citadas.

En Horacio (1929, 2003), una cantidad significativa de menciones a la risa se encuentra en el libro I. Gowers (2003: 56) opina que lo autobiográfico es el motor que impulsa el libro I de Sátiras de Horacio. La risa en Horacio no necesariamente es autobiográfica, pero sí es parte de lo programático: quamquam ridentem dicere verum / quid vetat? (I, 1,24-25, ¿qué impide que quien ríe diga la verdad?). Es uno de los medios posibles de decir la verdad. Permite hacerlo de forma indirecta, no con la violencia de la diatriba sino con la sutileza de la ironía. Ahora bien, no es la risa el único medio posible, ni el único necesario: ergo non satis est risu diducere rictum / auditoris; et est quaedam tamen hic quoque virtus (I, 10, 7-8, pues, no basta con hacer abrir la boca de risa al oyente -y eso que hay en ello también cierta virtud-).

El procedimiento es consciente y persigue, por lo menos, tres fines: crítica, ridículo, complicidad. La crítica se aprecia en una referencia del satírico a su propia obra: la frase "facetus / pastillos Rufillus olet, Gorgonius hircum" (I, 2, 26-27, el elegante Rufilo huele a pastillas, Gorgonio a tigre)" recibe el comentario "ego si risi, quod ineptus / pastillos Rufillus olet, Gorgonius hircum, / lividus et mordax videor tibi?"' (I, 4, 91-93, Pero, si yo me reí de que el absurdo Rufilo huele a pastillas, Gargonio a tigre, ¿te parezco envidioso y mordaz?).

El ridículo está presente en el pasaje de la estatua de Príapo: canidiae dentis, altum Saganae caliendrum / excidere atque herbas atque incantata lacertis / vincula cum magno risuque iocoque videres (I, 8, 48-50, Te habrías partido de risa viendo a Canidia caérsele los dientes, a Sagana el postizo y de sus brazos las hierbas y los lazos de los encantamientos). Esta risa legitima un punto de vista: la superioridad frente a personajes moralmente inferiores. Quizás el uso más llamativo de la risa en Horacio es el de complicidad. Así, en el episodio del jurisconsulto que le ayuda con la demanda: solventur risu tabulae, tu missus abibis (II, 1, 86, La demanda acabará en risas y tú te irás libre de cargos).

Tres pasajes poseen una función argumentativa:

1. El ridículo en el episodio del scurra (degradación de la imagen del destinatario): prior Sarmentus 'equi te / esse feri similem dico.' ridemus, et ipse / Messius 'accipio,' caput et movet (I, 5, 5658, Primero Sarmiento: 'Digo que eres igual que el caballo salvaje'. Nos reímos y el propio Mesio dijo: 'Lo acepto', moviendo la cabeza).

2. El ridículo en el del empresario (exposición de una oposición ante un punto de vista): Persius exponit causam; ridetur ab omni / conventu; laudat Brutum laudatque cohortem (I, 7, 22-23, Persio expone su causa: se ríe toda la asamblea, cuando alaba a Bruto y a todo su séquito).

3. La complicidad en el del importuno (exposición de una aprobación ante un punto de vista): nutans, / distorquens oculos, ut me eriperet. male salsus / ridens dissimulare (I, 9, 64-66, le hice señas con cabeza y ojos para que me sacara de allí. Sonreía guasón y disimulaba).

La risa no es uno de los temas principales en Persio $(1918,1991)$. Sin embargo, es importante por dos motivos: en primer lugar, por las constantes referencias a Horacio y su risa; en segundo, porque el mismo Persio define su propósito a partir de la risa. Littlewood (2002: 63) señala que todas las sátiras de Persio están llenas de alusiones específicas a Horacio. Un ejemplo, relacionado con la risa: omne vafer vitium ridenti Flaccus amico / tangit (I, 116-117, Horacio pone maliciosamente el dedo en la llaga a 
su amigo, que se monda de risa). A su vez, en su sátira programática, Persio dice: (...sum petulanti splene) cachinno (I, 12, Tengo hiel agresiva y suelto la carcajada), y hoc ego opertum, / hoc ridere meum, tam nil, nulla tibi vendo / Iliade (I, 121-123, Este misterio de mi pensamiento, esta risa mía, esta nadería, no te la vendo por una Ilíada).

La risa es parte de la intención satírica de Persio. Desde una perspectiva filosófica y educativa, resulta necesario conocer sobre la risa, puesto que esta es moneda común entre los jóvenes, quienes prefieren la entretención al provecho. Si bien no hay en Persio autoironía, como en Horacio, sí hay consciencia de los juicios de valor de la otra parte: his populus ridet, multumque torosa iuventus / ingeminat tremulos naso crispante cachinnos (III, 86-87, Estos asuntos hacen reír a la gente, y la juventud nervuda frunce la nariz y suelta la vibrante carcajada). No se han encontrado en él usos argumentativos de la risa.

Juvenal $(1918,1991)$ no ríe de los vicios, como Horacio; se indigna ante ellos. No sería, pues, de esperarse una risa con la misma función. Esta aparece como antítesis de la indignàtio y se ejemplifica muy bien en el paralelismo que señala Keane (2003: 270) de que, en dos contextos programáticos, se oponen la risa de Demócrito $(\mathrm{X})$ y la indignātio de Juvenal (I). Son dos respuestas distintas ante un fenómeno similar, la degeneración de las costumbres: tunc quoque materiam risus invenit ad omnis / occursus hominum (X, 47-48, Pero Demócrito también en su época se topó con materia de risa en cualquier encuentro con los hombres). Allí donde Juvenal se indigna, Demócrito se ríe.

Si el satírico no ríe, ¿quiénes lo hacen? Un infame, cuya risa, justificada en ciertos entornos sociales, se vuelve inaceptable en determinadas condiciones morales: loripedem rectus derideat, Aethiopem albus; / quis tulerit Gracchos de seditione querentes? (II, 23-24, El de buena planta puede reírse del zancajoso, el blanco del etíope, pero ¿quién tolerará que los Gracos protesten de una rebelión?). Un griego: rides, maiore cachinno / concutitur; flet, si lacrimas conspexit amici (III, 100-101, Si te ríes, a un griego le sacuden carcajadas mayores, llora si ve lágrimas en un amigo). El público de las comedias: Vrbicus exodio risum movet Atellanae / gestibus Autonoes (VI, 71-72, Úrbico [en el exodio] hace mondar de risa gesticulando como una Autónoe en la farsa atelana). En suma, los practicantes de los vicios censurados por el satírico. Una vez más, seres moralmente inferiores. Se asemeja al uso de la risa en Horacio para ridiculizar, pero es distinto al añadir la indignación.

Hay una cita con función argumentativa:

4. Los clientes que ríen de las cortesanas (exposición de una oposición ante un punto de vista): 'quem rides? aliis hunc mimum! (VI, 365, 28, ¿De quién te ríes? ¡A otro con esta farsa!).

Horacio ríe; Persio pone la risa al servicio de la educación; Juvenal opone la risa a la indignación. Se emplee o no el mecanismo de la risa, se acepta, en todo caso, su utilidad. Tal es la situación en la sátira, pero ¿qué sucede en los otros géneros?

En primer lugar, se aborda el epigrama. De acuerdo con Muñoz (1992: 43), Marcial es "el humorista con mayúsculas y por antonomasia de la Antigüedad”. En Marcial (1925, 2003), la risa puede llegar a ser cruel si se presta para la diatriba, si se aleja del rìdiculum līberāle (propio de la sátira) y se acerca al rìdiculum illïberāle (propio del epigrama), o si cambia la ironía por el sarcasmo. Esta risa es digna de temor, como en el caso de la vieja que, ya sin dientes, no puede reír como cuando era niña, sino que debe llorar: 'Ride si sapis, o puella, ride'... Quare si speculo mihique credis, / Debes non aliter timere risum... vita / Et quidquid lepida procacitate / Laxat perspicuo labella risu... Plora, si sapis, o puella, plora (II, 41, 'Ríete, si tienes juicio, niña, ríete'... Por tanto, si crees al espejo y a mí, debes temer la risa... Evita todo lo que con una graciosa procacidad relaja los labios en carcajada abierta... 'Llora, si tienes juicio, niña, llora'). El caso característico de risa por temor 
es la risa nerviosa, que se encuentra también en el ejemplo del bebedor que teme perder su ojo: Ridens Phryx oculo 'Valebis' inquit (VI, 78, Entre risas, dijo Frige a su ojo: ‘Cuídate!’).

La risa puede ser motivo de alegría, sobre todo en el contexto del banquete. Tal es el caso del médico: hilaris cenavit (VI, 53, cenó entre risas). También puede evocar lo grotesco, asociada a lo bajo corporal: Pedere te mallem: namque hoc nec inutile dicit / Symmachus et risum res movet ista simul: / Quis ridere potest fatui poppysmata cunni? (VII, 18, Más quisiera que te peyeras, ya que esto tampoco es inútil, dice Símmaco, y es cosa ésa que, a la vez, mueve a la risa ¿quién puede reírse de los traques de un coño fatuo?).

Presenta un caso de tipo argumentativo:

5. La complicidad del satírico ante la pregunta por su oficio (promoción de la imagen del emisor): 'Tune es, tune' ait 'ille Martialis, / Cuius nequitias iocosque novit, / Aurem qui modo non habet Batavam?' / Subrisi modice (VI, 82, ¿ ¿No eres tú, sí, tú, ese Marcial cuyas maldades y chanzas los conoce cualquiera, con tal que no tenga oreja bátava?' Esbocé una sonrisa).

En segundo lugar, se trabaja la novela. El tema de la clasificación del Satiricón en un género es bastante complejo. Carmignani (2009: 89) lo ubica como "novela cómico-paródica escrita bajo la forma del prosimetrum”, con algunas influencias de la fábula milesia y de otros géneros. Lo más importante, para el análisis de la risa, es su vinculación con la sátira.

En Petronio (1913, 1993), la risa sirve para interrumpir, para provocar la burla, para expresar temor, pudor y alivio. Los ejemplos, respectivamente, son: Itaque ex turpissima lite in risum diffusi pacatius ad reliqua secessimus (10, Así esta discusión tan vergonzosa se transformaba poco a poco en carcajadas y, ya más tranquilos, pasamos a otras cosas); praeclusisque foribus ridere acumen non minus cocionum quam calumniantium coepimus (15, A puertas cerradas nos divertimos a carcajadas del cacumen de los mercaderes y de nuestros acusadores); Complosis deinde manibus in tantum repente risum effusa est, ut timeremus (18, Luego, dando palmadas, soltó tal carcajada que nos infundió pavor); Ac ne Giton quidem ultimo risum tenuit, utique postquam virguncula cervicem eius invasit et non repugnanti puero innumerabilia oscula dedit (20, Ni Gitón pudo aguantar la risa sobre todo cuando en un momento dado la muchachita le tomó la cabeza en sus manos y le dio innumerables besos); Stabat inter haec Giton et risu dissolvebat ilia sua (24, Gitón, parado ante nosotros, se rompía los ijares de risa).

El texto cuenta con dos ejemplos relevantes para la argumentación:

6. Interrupción de una relación sexual (degradación de la imagen del destinatario): cum Ascyltos furtim se foribus admovit discussisque fortissime claustris invenit me cum fratre ludentem. Risu itaque plausuque cellulam implevit (11, Ascilto que se había acercado de puntillas a la puerta, rompió estrepitosamente la cerradura y me cogió de sorpresa en pleno jugueteo con mi querido. Llenó el cuarto con carcajadas y aplausos).

7. Ridículo de una disputa (exposición de una oposición ante un punto de vista): nam et cociones qui ad clamorem confluxerant, nostram scilicet de more ridebant invidiam, quod pro illa parte vindicabant pretiosissimam vestem, pro hac pannuciam ne centonibus quidem bonis dignam (14, Los chamarileros, atraídos por nuestras curiosa disputa, reían a mandíbula batiente y no sin motivo: por un lado reivindicaba una finísima prenda, y por el otro, unos andrajos que ni aún en retazos podían valer algo). 


\section{Conclusiones}

A partir de los retóricos latinos, se ha entendido la risa en términos de una valoración, efectuada en un contexto específico. Gracias al modelo axiológico de Stern, se ha podido establecer una conexión entre risa y argumentación, por medio de los valores. Estos planteamientos se han visto reforzados por la teoría de argumentación: por un lado, la argumentación depende de juicios de valor, que se fundamentan en jerarquías de valores, principalmente abstractos; por otro, la ironía se ofrece como la estructura más apropiada para la argumentación por el ridículo, la cual equivaldría a la demostración por reducción al absurdo.

Se ha brindado una tipología de los valores argumentativos de la risa: a) promoción de la imagen del emisor, b) degradación de la imagen del destinatario, c) exposición de una oposición ante un punto de vista, d) exposición de una aprobación ante un punto de vista y e) establecimiento de una comunión con el auditorio. Y se ha sugerido una vía de análisis para el valor argumentativo de los chistes, mediante la pragmática.

En la literatura de espíritu satírico se ha analizado la sátira, el epigrama y la novela. Horacio y Persio incluyen la risa como parte de lo programático; Juvenal la opone a la indignātio. En Horacio, la risa sirve para la crítica, el ridículo y la complicidad; en Persio, para la filosofía; en Juvenal, para un tipo distinto de ridículo. Con sus epigramas, Marcial hace su aporte con la risa de temor, más allá de lo cómico. Adicionalmente, en la novela de Petronio, la risa permite interrumpir, provocar la burla, expresar temor, pudor y alivio.

Se hallaron siete casos de risas con valores argumentativos. Por géneros: cuatro en la sátira ( 1 , $2,3,4)$, una en el epigrama (5), dos en la novela (6, $7)$. Por autores: tres en Horacio $(1,2,3)$, una en Juvenal (4), una en Marcial (5), dos en Petronio $(6,7)$. Por propósitos: cinco para el ridículo $(1,2$, $4,6,7)$, dos para la complicidad $(3,5)$. Por valores argumentativos: dos con degradación de la imagen del destinatario $(1,6)$, tres con exposición de una oposición ante un punto de vista $(2,4,7)$, una con exposición de una aprobación ante un punto de vista (3), una con promoción de la imagen del emisor (5). No se encontraron ejemplos de comunión con el auditorio, una función más de carácter retórico. Tampoco se identificaron ejemplos de risas con valores argumentativos en Persio.

\section{Bibliografía}

Barrow, R. (2002). Los romanos. México: FCE.

Carmen, M. (2010). El Icaromenipo de Luciano de Samosáta: entre el spoudogeloīon y la carnavalesca de Bajtín. Estudios griegos e indoeuropeos. 20, 215-230.

Carmignani, M. (2009). “El Satyricon como novela: la sátira menipea y los nuevos descubrimientos papiráceos". Circe. 13, 75-91.

Cattani, A. (2003). Los usos de la retórica. Madrid: Alianza.

Cicero. (1902) Rhetorica. Tomus I. Oxonii: Typographeo Clarendoniano. Available at: www.perseus.tufts.edu

Cicero. (1911) Rhetorica. Tomus II. Oxonii: Typographeo Clarendoniano. Available at: www.perseus.tufts.edu

Cicerón. (1913) Obras completas. Traducción de Marcelino Menéndez. Madrid: Hernando.

Conley, T. (2004) What Jokes Can Tell Us About Arguments. In W. Jost \& W. Olmsted (eds.) A Companion to Rhetoric and Rhetorical Criticism. United Kingdom: Blackwell Publishing.

Gil, L. (1997). "La risa y lo cómico en el pensamiento antiguo”. Cuadernos de Filología Clásica. $7,29-54$. 
González, C. (2002-2003). “Aproximaciones a la definición, origen y función de la risa en la comedia latina”. Minerva. 16, 77-86.

Gowers, E. (2003). Fragments of Autobiography in Horace Satires I. Classical Antiquity. 22 (1), 55-91. Retrieved from JSTOR Database.

Hodgart, M. (1969). La sátira. Madrid: Guadarrama.

Horacio (2003) Sátiras. Epístolas. Arte poética. Edición bilingüe y traducción de Horacio Silvestre. Madrid: Cátedra.

Horatius (1929) Satires, Epistles and Ars Poetica. Cambridge: Harvard University Pres. Available at www.perseus.tufts.edu

Juvenal. Persio. (1991). Sátiras. Edición y traducción de Manuel Balasch. Madrid: Gredos.

Juvenal. Persius. (1918). Satires. New York: William Hinemann. Available at www.perseus.tufts. edu

Keane, C. (2003). "Theatre, Spectacle and the Satirist in Juvenal”. Phoenix. 57 (3-4), 257 275. Retrieved from JSTOR Database.

Littlewood, C. (2002). Integer Ipse? Self-Knowledge and Self-Representation in Persius Satires 4. Phoenix. 56 (1-2), 56-83. Retrieved from JSTOR Database.

Marcial (2003). Epigramas. Edición y traducción de José Guillén. Zaragoza: Institución Fernando el Católico.

Martial (1925). Epigrammaton libri. Leipzig: Teubner. Available at www.perseus.tufts.edu

Martínez, F. et al. (2008). Metodología para el estudio de la sátira mediática. I+C Investigar a Comunicación. Santiago de Compostela: Asociación Española de Investigación de la Comunicación.
Mas, S. (2015). Verecundia, risa y decoro: Cicerón y el arte de insultar. Isegoría. 53 (2), 445-473.

Monsalve, A. (1992). Teoría de la argumentación. Medellín: Universidad de Antioquía.

Muñoz, M. (1992). Roma ludens: reflejos del humor en la literatura latina. Estudios Clásicos. 34 (101), 23-46.

Paraíso, I. (1997). De risu. Cicerón, Quintiliano, Bergson, Freud ante la risa. Juan Labieno et al. (eds.) Retórica política e ideología. Desde la Antigüedad a nuestros días. Vol. II. Salamanca: Universidad de Salamanca.

Petronio (1993). El Satiricón. Edición y traducción de Julio Picasso. Madrid: Cátedra.

Petronius (1913). Satyricon. New York: William Hinemann. Available at www.perseus.tufts. edu

Pollock, J. (2003). ¿Qué es el humor? Buenos Aires: Paidós.

Quintilian. (1921). Institutio Oratoria. Cambridge: Harvard University Press. Available at: www. perseus.tufts.edu

Quintiliano. (2004). Instituciones oratorias. Traducción de Ignacio Rodríguez y Pedro Sandier. Madrid: Hernando. Disponible en: www.cervantesvirtual.com

Segura, S. (2003). Nuevo diccionario etimológico latín-español y de las voces derivadas. Bilbao: Universidad de Deusto.

Stern, A. (1950). Filosofía de la risa y el llanto. Buenos Aires: Imán.

Vega, L. y Olmos, P. (eds.) (2012). Compendio de lógica, argumentación y retórica. Madrid: Trotta. 